\title{
Espectrômetro amador: quantificando comprimentos de onda ${ }^{+*}$
}

\author{
Francisco Catelli ${ }^{1}$ \\ Odilon Giovannini ${ }^{2}$ \\ Mestrado Profissional em Ensino de Ciências e Matemática \\ Universidade de Caxias do Sul \\ Caxias do Sul - RS \\ Suzana França de Oliveira ${ }^{3}$ \\ Instituto de Desenvolvimento Educacional do Alto Uruguai \\ Faculdade IDEAU \\ Colégio Santa Clara \\ Getúlio Vargas - RS
}

\section{Resumo}

Esse trabalho descreve, passo a passo, a construção de um espectrômetro, com base em materiais de fácil obtenção e manipulação. A física envolvida, a óptica ondulatória, é contextualiza historicamente de forma breve; o princípio de Huygens é apresentado também resumidamente. A seguir, a construção do espectrômetro é detalhada e as imagens de alguns espectros de emissão são apresentadas. Por fim, algumas dentre as muitas explorações possíveis são sugeridas e a conclusão aponta para dois aspectos em especial. No primeiro, a construção do dispositivo pode dar ocasião a uma atividade teórico-prática motivadora. O segundo aspecto destaca o potencial de investigação de espectros, tanto de emissão quanto de absorção que se abre para os estudantes, propiciando assim ambientes de aprendizagem de grande potencial motivador.

Palavras-chave: Óptica Física; Espectrômetro Amador; Atividades Investigativas.

\footnotetext{
+Amateur's spectrometer: measuring wavelengths

* Recebido: junho de 2017. Aceito: setembro de 2017.

${ }^{1}$ E-mail: Fcatelli@ucs.br, ${ }^{2}$ E-mail: ogiovanj@ucs.br, ${ }^{3}$ E-mail: sfoliveira2@ucs.br
} 


\begin{abstract}
This work describes, systematically, the construction of a spectrometer based on readily available materials and easy handling. The physics involved, wave optics, is historically contextualized briefly; the principle of Huygens is also presented. Next, the construction of the spectrometer is detailed; the images of some emission spectra are presented. Finally, some of the possible exploitations are suggested; and the conclusion points to two aspects in particular. At first, the construction of the device can give occasion for a motivating theoretical and practical activity. The second aspect highlights the potential of the research activity, including emission and absorption spectra that opens to students, thereby providing great motivating learning environments.
\end{abstract}

Keywords: Physical Optics; Amateur's Spectrometer; Investigative Activities.

\title{
I. Introdução
}

Einstein disse certa vez: "Todos estes cinquenta anos de reflexão não me trouxeram mais perto da resposta à pergunta: o que são os quanta de luz?"2 Um possível sentido para essa afirmação é o de que a ideia de luz tem sim atravessado os séculos e evoluído consideravelmente, mas uma resposta cabal a essa questão ainda não está claramente posta. Uma das concepções mais imediatas e intuitivas a respeito da luz é a de que ela se propaga em linha reta, e essa concepção foi (e ainda é) muito prolífica, para as mais variadas aplicações. No que diz respeito a esse trabalho, a ideia de partida é a de que a luz pode ser entendida, em determinadas condições, como uma "onda". Assim, a decomposição da luz branca em suas cores componentes, por exemplo, pode ser explorada a partir de seu caráter ondulatório, e é disso que no ocuparemos predominantemente aqui. Mas, mesmo esse caráter ondulatório, que possibilitou ao longo da história de ciência um sem número de sucessos, encontrou também percalços. Foi necessário criar uma nova entidade física, o fóton, o qual tem propriedades essencialmente não "clássicas", quer dizer, ele nem apresenta características de partícula, tal como uma partícula seria concebida classicamente, nem características de onda. Feynman dizia que as ondas são apenas dispositivos convenientes para o cálculo das probabilidades de interação de um fóton com um detector. Não nos ocuparemos aqui dessa visão mais moderna de fóton; um excelente artigo, em nível introdutório, para quem se interessa por uma visão mais completa do que é um

\footnotetext{
2 No original: "All these fifty years of pondering have not brought me any closer to answering the question: what are light quanta?" (Marburger, 1996).
} 
fóton é o de Marburger, 1996. No restante do trabalho discutiremos como números ("comprimentos de onda") podem ser associados às "ondas de luz" e, por extensão, às "cores", através de um dispositivo experimental, de construção e operação bastante simples. Daremos também ênfase às diferentes formas de uso desse dispositivo.

\section{Justificativa}

Na literatura de didática da física encontram-se diversas referências a espectrômetros (ver, por exemplo, OLIVEIRA; LEITE, 2016; LÜDKE, 2010) e espectroscópios (também como exemplo, GARCIA; KALINOWSKI, 2004; CATELLI; PEZZINI, 2004). Como os próprios nomes sugerem, "espectroscópios" são dispositivos que permitem a visualização de espectros; se existir a possibilidade de medição de comprimentos de onda, então o termo a ser usado é "espectrômetro", o que é o caso desse artigo. Alguns dispositivos experimentais associados ao ensino e à aprendizagem, em geral da Física, mas não exclusivamente, foram apresentados em diversos artigos ao longo do tempo, mas o instrumental necessário é por vezes pouco acessível (é necessário equipamento um tanto especializado), e a construção, relativamente complexa; por fim, o ajuste desses dispositivos é, em geral, delicado. De toda a forma, esses projetos são desafiantes, e seguramente atraem um certo número de estudantes.

Nesse artigo, o foco está dirigido a projetos de execução simples. O dispositivo básico aqui proposto consiste de um elemento dispersor de luz (rede de difração) feito a partir de CDs graváveis, fora de uso; diversos tipos de espectroscópios, feitos com esses dispositivos dispersores são sugeridos por Köppen ${ }^{3}$. O instrumental que é proposto aqui é de fato de construção muito simples, e faz uso de material não especializado (CDs graváveis, cartolina, fita adesiva). A transformação desse dispositivo em um instrumento de medida faz uso de princípios básicos da óptica ondulatória, e também é de fácil execução. Finalmente, a operação desse dispositivo segue a mesma linha: é bastante intuitiva, e não exige nenhuma habilidade especial.

A função básica do dispositivo aqui proposto é a de permitir medições de comprimentos de onda. Dito de outra forma, trata-se de atribuir números a comprimentos de onda; encontraremos aí uma primeira questão: é possível atribuir um número (acrescido de uma unidade) a qualquer cor que pode ser visualizada? Por exemplo, podemos atribuir um número à "cor lilás"? O caminho até justificar uma resposta negativa a essa questão é curioso, e pode ser significativamente enriquecido com o acréscimo de dispositivos tais como o que é proposto aqui.

\section{O que é "luz"?}

Desde há muito tempo, a propagação aparentemente retilínea da luz tem sido explorada. Registros do emprego da câmara escura remontam a cinco séculos AC; consta também

\footnotetext{
$3<$ http://astro.u-strasbg.fr/ koppen/spectro/typese.html>.
} 
que Aristóteles a teria mencionado (século III AC) ${ }^{4}$. Pintores medievais, com o auxílio de imagens produzidas por grandes câmaras escuras, delineavam sobre uma tela os contornos de seus modelos, como esboço para as pinturas que se sucederiam. Essa propagação em linha reta ainda hoje faz parte do repertório das aulas de óptica, quando os professores exploram a formação de imagens por espelhos e lentes. "Traçados de raios" mais sofisticados são de uso corrente em projetos de engenharia óptica, e isso é rotina em pleno século XXI. Mas, basta observar - digamos - a chama de uma vela através de uma fenda estreita, e enfrentaremos dificuldades praticamente intransponíveis ao tentar explicar o que observamos através dos preceitos da propagação retilínea da luz.

Se procurarmos nos livros texto, mesmo os de nível universitário, encontraremos lá que a luz é "[...] uma onda eletromagnética” (HALLIDAY; RESNICK, WALKER; v. 4, p. 1) A exploração da luz como onda (proposta originalmente por Huygens), e depois como onda eletromagnética (Maxwell, Hertz e outros), é deveras profícua, e como foi dito na introdução, é dela que nos ocuparemos aqui. No entanto, se o que estiver em jogo - por exemplo - for um processo de interação da luz com a matéria (pense na pele humana, ao ser exposta ao Sol), a hipótese da luz como onda já não será satisfatória, será necessário o concurso aos fótons, como já mencionado. Assim, a física estuda o comportamento da luz por meio de "modelos de luz", cada um dentro de um determinado domínio, e, nesse sentindo, Knight (2009) afirma que " $a$ luz é o camaleão do mundo físico".

A evolução das sucessivas ideias do que seria a luz pode ser vislumbrada parcialmente a partir do quadro apresentado na Fig. 1; vários exploradores da natureza da luz são situados de acordo com seus anos de nascimento e morte. O quadro também permite identificar quem foram alguns dos principais adeptos da propagação retilínea, da natureza ondulatória e da natureza corpuscular da luz. Se os estudantes ficarem surpresos com o fato de várias teorias que explicam o comportamento da luz "conviverem" de maneira relativamente harmônica numa mesma época, o professor pode argumentar que filósofos da ciência, como por exemplo, Harry Laudan (ver um resumo de suas ideias em MASSONI, 2005, p. 33), defendem que "[...] a coexistência de tradições de investigação rivais e de teorias rivais é uma regra para o avanço da ciência". Nesse texto, como já adiantado, a luz será vista a partir de suas propriedades ondulatórias (“clássicas").

\section{Fundamentação teórica: luz como onda, interferência}

Serão apresentados a seguir alguns elementos estruturantes do ponto de vista conceitual para esse trabalho. Maiores detalhes (conceituais e formais) podem ser encontrados em praticamente todas as obras de Física introdutória para a Universidade, tais como Halliday, Resnick e Walker (2014, v. 4, cap. 36) e Tipler e Mosca (2011, v. 2, cap. 33). Na abordagem a

\footnotetext{
${ }^{4}$ Ver, por exemplo, <http://blog.fotografiabasica.com.br/2016/01/26/historia-da-fotografia-camara-escura-pinturas-quarto-invertido-parte-1/>.
} 
seguir, a meta é uma explicação conceitual, sob o viés da óptica ondulatória, do porquê a luz branca se separa em suas cores componentes ao passar por uma fenda dupla.

Um dos modos mais férteis de pensar a luz como onda foi o proposto por Hans Christiaan Huygens (1707) $)^{5}$, contemporâneo e amigo de Newton, que, por sua vez, defendia a natureza corpuscular da luz. Enquanto Newton $(1704)^{6}$ propunha a propagação da luz como corpúsculo, o que segundo suas leis exigiria uma velocidade de propagação maior - por exemplo - na água do que no ar, Huygens sugeria uma propagação em forma de onda, tal como colocado de forma bastante concisa na legenda da Fig. 2. Cada elemento de uma onda, segundo Huygens, podia ser imaginado como consistindo de uma "ondícula", que se propagaria segundo um padrão circular (no plano, por exemplo, a superfície da água) ou esférico (no espaço, por exemplo, uma onda sonora). A envoltória desse padrão de ondículas definiria a nova frente de onda.

Uma consequência notável dessa ideia é a de que, se um obstáculo munido de uma pequena abertura for interposto no percurso da onda (plana, por exemplo), um padrão de ondas circulares emergirá do outro lado, como sugere a Fig. 2. A esse fenômeno dá-se o nome de "difração" (HALLIDAY; RESNICK; WALKER, 2014).

Na Fig. 3, o mesmo padrão de ondas planas incide numa barreira, dessa vez munida de duas aberturas (uma figura semelhante foi apresentada por Thomas Young, em 1801). Dessa vez, dois padrões de ondas circulares (no plano; no espaço seriam "calotas" esféricas) aparecem do lado oposto da barreira. Essas ondas, ao se sobreporem, interferem umas com as outras, de tal sorte que, quando a parte mais elevada de uma das ondas ("crista") se sobrepõe à crista da outra onda, ocorrerá a chamada "interferência construtiva". Considere, por exemplo, o ponto "p" na figura 3. Partindo da fenda inferior, são seis ondas semicirculares; mas, partindo da fenda superior, apenas cinco ondas serão contadas. Como a sexta onda (fenda inferior) chega em máximo no ponto $\mathrm{p}$, e a quinta onda também chega nesse mesmo ponto em máximo (vinda da fenda superior) teremos aí uma interferência completamente construtiva.

Para entender melhor a situação: se fossem ondas na água de um lago, ao passar de barco por uma dessas regiões sentiríamos uma grande turbulência - ondas "altas". Alguns desses padrões de interferência construtiva são identificados por pequenos círculos na Fig. 3 (o padrão central, perpendicular à barreira, e os padrões imediatamente acima e imediatamente abaixo desse são destacados). Inversamente, quando a crista de uma onda circular se sobrepõe ao "vale" da outra, teremos uma interferência (completamente) destrutiva. Na imagem do barco, essas seriam regiões onde reina calmaria - não haveria ondas aí.

Por fim, um detalhe adicional, o mais relevante para esse trabalho: à esquerda, na Fig. 3, um comprimento de onda - a distância entre duas ondas contíguas - é maior do que o padrão

\footnotetext{
5 O texto original do "Treatise on Light" de Huygens pode ser baixado gratuitamente em pdf em $<$ https://ia600307.us.archive.org/13/items/treatiseonlight031310mbp/treatiseonlight031310mbp.pdf>.

6 Um arquivo pdf com a versão original da Óptica de Newton pode ser acessado gratuitamente em $<$ http://brizhell.org/Newton_Speckles/Opticks\%20-\%20scan\%20from\%20original\%20manuscript\%20-\%20I.\% 20Newton.pdf>.
} 
de ondas planas da figura da direita. A figura à esquerda representa, em vermelho, um comprimento de onda grande, quando comparado ao comprimento de onda da figura da direita, em azul. As aberturas, nas duas figuras, são idênticas, tanto nas suas larguras quanto na distância entre seus centros.

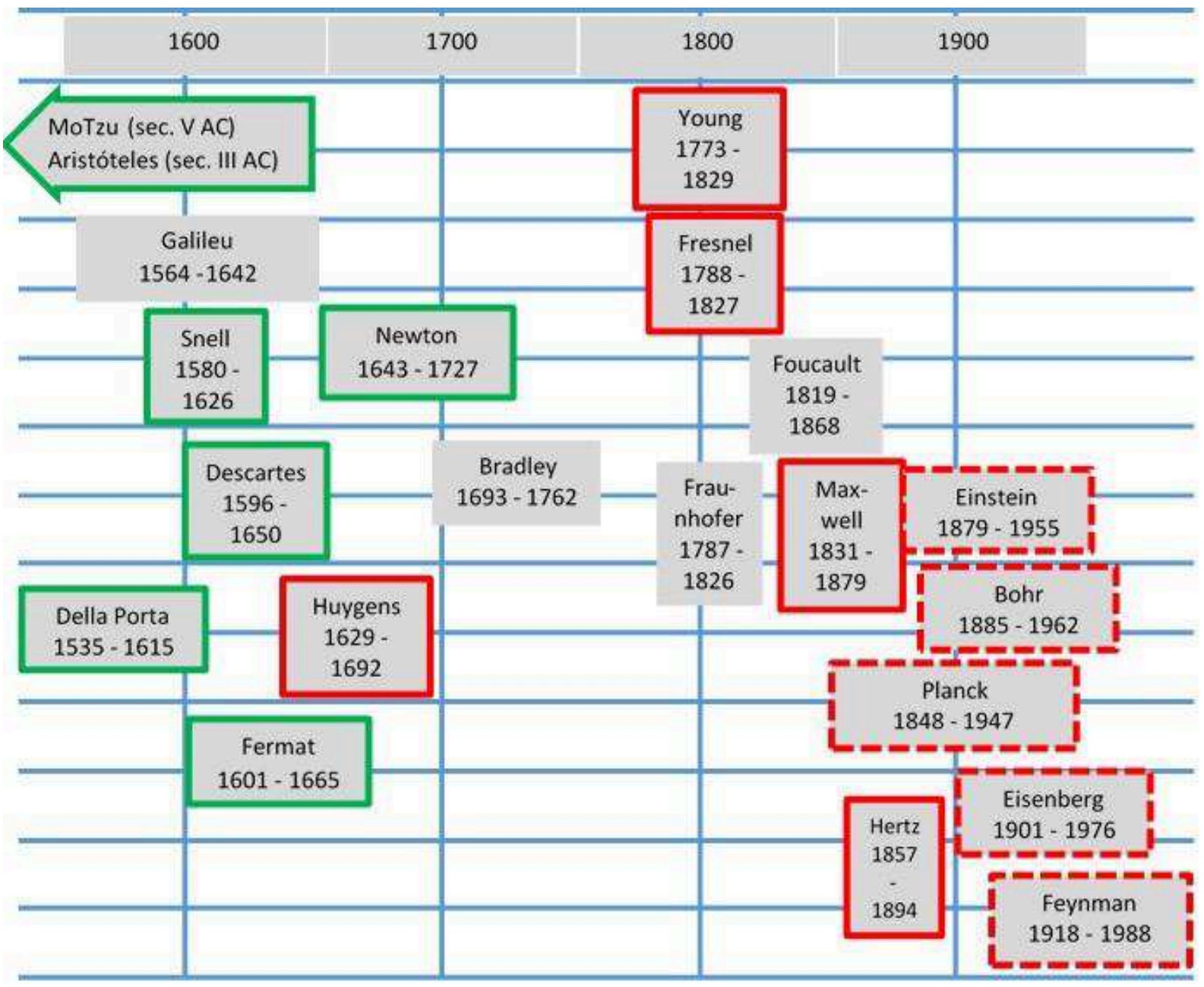

Fig. 1 - Linha do tempo, para alguns dos principais nomes da óptica; a maior parte deles é mencionada nesse trabalho. Cada quadro inicia no ano de nascimento do cientista aí referido, e termina no ano de sua morte. É possível ver, por exemplo, que logo depois da morte de Galileu, nasce Newton. Ou que Fraunhofer viveu aproximadamente na mesma época de Fresnel, e que Max Planck viveu quase 100 anos. A moldura em verde cerca os nomes ligados ao modelo corpuscular da luz; em vermelho, os nomes ligados ao modelo ondulatório da luz. Os quadros com borda em pontilhado vermelho referem-se aos cientistas que ajudaram a estabelecer a luz como um ente essencialmente quântico, ofóton. (Fonte: produzido pelos autores) 


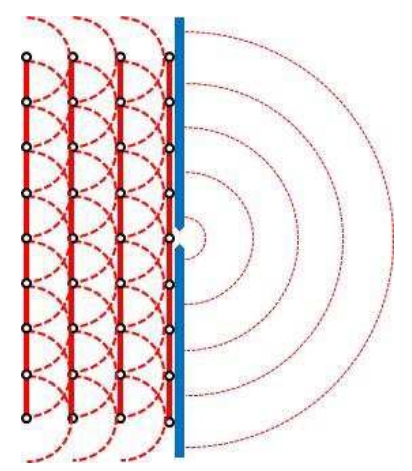

Fig. 2 - Uma onda plana propagando-se, por exemplo, na água. Segundo Huygens, cada ponto de cada onda plana pode ser pensado como uma "ondícula", circular. Após um determinado tempo, a envoltória dessas ondículas determinará a posição da nova frente de onda. Se uma barreira com uma pequena abertura estiver no caminho da onda plana, pode-se imaginar que apenas uma das ondículas (ou uma pequena parte delas) passará, e do outro lado formar-se-á uma onda circular. Esse fenômeno é conhecido como "difração"
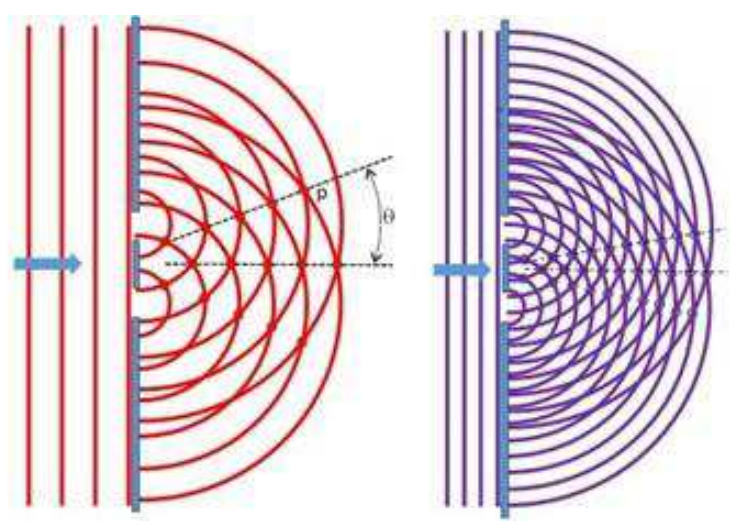

Fig. 3 - Uma onda plana incide numa barreira munida de duas aberturas. No desenho à esquerda, o comprimento de onda (espaçamento entre duas ondas planas contíguas) é maior que o espaçamento das ondas planas da figura da direita (esse espaçamento se mantém após a passagem pelas aberturas). Ao emergir do outro lado, as ondas assumem (no plano) um padrão circular, e as ondas que emergem da abertura superior interferem com aquelas oriundas da abertura inferior. Parte do padrão de interferência foi marcado nas duas figuras através de pequenos círculos; note que esses padrões estão mais próximos uns dos outros na configuração onde o comprimento de onda é menor (figura da direita, em azul).

Observemos os padrões de interferência construtiva (marcados por pequenos círculos) nas duas figuras. O padrão central, indicado pela linha pontilhada perpendicular à barreira, aparece na mesma posição, na figura da esquerda e na figura da direita. Entretanto, e esse é o resultado que nos interessa aqui, os padrões imediatamente acima e abaixo do padrão central 
aparecem próximos a esse para pequenos comprimentos de onda (figura em azul) e mais distantes, para grandes comprimentos de onda (figura em vermelho). Ou, dito de outra forma, o ângulo $\theta$ da figura à esquerda é maior do que seria o mesmo ângulo na parte à direita da Fig. 3.

A consequência mais significativa desse fato é a seguinte: se, numa barreira munida com duas aberturas, incidir uma "mistura" de ondas planas de grande comprimento de onda e ondas planas de pequeno comprimento de onda, do outro lado dessa abertura o padrão central de interferência construtiva reconstituirá fielmente essa mistura. Mas os demais padrões, não! Isso significa que, por exemplo, o primeiro padrão construtivo das ondas vermelhas aparecerá mais distante do padrão central, e o padrão azul, mais próximo. Então, esse dispositivo de dupla abertura ${ }^{7}$ permitirá a separação das ondas "vermelhas" e "azuis", e esse é o princípio básico que permite um sem número de explorações, experimentos, verificações e medições de rotina num campo da Física que, ao tratar em especial da luz, tem nome próprio: a "espectroscopia".

Seria uma missão quase impossível relatar, de forma minimamente fiel e completa, as consequências práticas da possibilidade de separar "misturas" de ondas de comprimentos (de onda) diferentes. Nem tentaremos. Diremos apenas que, no caso da luz, visível ou não, todos os ramos da Engenharias fazem uso da espectroscopia, em maior ou menor grau. Na Medicina, tanto no campo da pesquisa, quanto no campo dos exames de rotina, equipamentos que separam diferentes comprimentos de onda de luz são rotineiros. Na Química (mas não só aí), espectrofotômetros são instrumentos de uso constante; o próprio nome do instrumento merece uma consideração breve: "espectro" indica que luz (absorvida, emitida, refletida) foi decomposta; "fotômetro" indica que a intensidade desses vários comprimentos de onda é quantificada. Por fim, na astronomia e astrofísica, praticamente tudo o que sabemos dos corpos celestes, tais como cometas, planetas, estrelas e galáxias ${ }^{8}$, nos é dado pela análise da luz que delas recebemos. E a grande maioria dessas informações é acessível a partir da decomposição da luz em seus comprimentos de onda componentes.

Do ponto de vista quantitativo, considere novamente o ponto "p" na Fig. 3, que denota uma interferência construtiva, ou máximo. A posição angular desse máximo, ou de qualquer outro (desconsiderando o máximo central), a uma distância grande das aberturas, é dada por

\footnotetext{
${ }^{7}$ Prismas (empregados por Newton, por exemplo, nos seus estudos de decomposição da luz branca em suas cores componentes) também são importantes como dispositivos técnicos para a prática da espectroscopia, mas não serão tratados nesse trabalho.

8 Já é possível afirmar que essa situação está mudando: ondas gravitacionais foram detectadas de forma inequívoca recentemente (veja, por exemplo, https://www.ligo.caltech.edu/). Então, a nossa "janela" para o universo não está mais restrita exclusivamente às ondas eletromagnéticas. Entretanto, cabe ressaltar que o LIGO, talvez o dispositivo experimental mais sofisticado já construído pelo ser humano, é um interferômetro, que opera na base da interferência de ondas eletromagnéticas; essa interferência captura a variação no comprimento dos ramos do interferômetro, e essa variação é a evidência experimental da "passagem" de uma onda gravitacional. Então, ainda dependemos das ondas eletromagnéticas para "ver o mundo", mesmo que sob a "ótica" das ondas gravitacionais. Para os detalhes básicos de funcionamento, e a construção de um interferômetro "caseiro", veja, por exemplo, https://periodicos.ufsc.br/index.php/fisica/article/view/6694/6161.
} 


$$
m \lambda=d \operatorname{sen} \theta
$$

na qual $\lambda$ é o comprimento de onda, $\theta$ aparece representado na Fig. 3, $d$ é distância entre as duas aberturas e $m$, igual a 1, 2, 3, ... é o número de ordem ( $m=1$ aparece destacado na Fig. 3).

Nesse trabalho, usaremos dispositivos dispersores denominados "redes de difração", dispositivos que contém um grande número de "aberturas", ou linhas, que desempenham um papel semelhante, do ponto de vista da luz que nelas incide, aos das duas aberturas acima descritas. A expressão (1) vale também para esses dispositivos, e será empregada a seguir para a construção de uma escala de medida de comprimentos de onda.

Há uma vantagem adicional em usar dispositivos de múltiplas aberturas ("fendas"): numa explicação deveras simplificada (mas mesmo assim correta) imagine que você observa uma fonte de luz estreita e extensa, uma lâmpada fluorescente tubular, por exemplo, através de um dispositivo de duas aberturas (fenda dupla), e depois, com um dispositivo de múltiplas aberturas (rede de difração). Se a lâmpada estiver na posição vertical, "cópias” dessa lâmpada serão visualizadas - digamos, à esquerda e à direita - para isso, as fendas deverão estar alinhadas paralelamente à lâmpada. Mas essas "cópias" serão borradas, e a expressão "cópia" é mesmo inadequada nesse caso. Mas se a lâmpada for observada através de uma rede de difração, as "cópias" se assemelharão muito mais à fonte, em especial no que diz respeito à nitidez. A justificativa formal desse efeito - o "poder de resolução" de uma rede de difração, pode ser encontrada, por exemplo, em Catelli et al. (2006).

\section{Construção e calibração do dispositivo}

Apresentamos na Fig. 4 o esboço do espectrômetro aqui proposto; todas as dimensões são apenas indicativas. Corte uma cartolina razoavelmente rígida de $15 \mathrm{~cm}$ por $15 \mathrm{~cm}$, e faça nela, a aproximadamente $4 \mathrm{~cm}$ de uma de suas bordas, por meio de um estilete, uma fenda de aproximadamente $1 \mathrm{~mm}$ por $15 \mathrm{~mm}$ (para um corte retilíneo da fenda, use uma régua de aço em conjunto com o estilete). Se a intenção for a de efetuar uma observação como a ilustrada na Fig. 8, corte a fenda mais larga, $5 \mathrm{~mm}$ por $15 \mathrm{~mm}$, por exemplo. Por meio de uma fita isolante preta, reduza a abertura dessa fenda para aproximadamente $1 \mathrm{~mm}$. Dessa forma, será possível efetuar também observações com a fenda larga, bastando para isso retirar a fita. A maior parte das aplicações descritas nesse trabalho será efetuada com fendas estreitas.

O passo seguinte consiste em cortar uma tira de cartolina de $6 \mathrm{~cm}$ por $24 \mathrm{~cm}$ e dobrala em "L", ao longo de seu comprimento maior; corte $4 \mathrm{~cm}$ da dobra de modo a poder formar duas abas, dobre-as para fora, como na Fig. 4. Cole essas abas na cartolina munida da fenda, com fita adesiva, cola, ou fita dupla face. O dispositivo dispersor, que será descrito a seguir, é então fixado à outra extremidade da tira, com tiras estreitas de fita adesiva (fita isolante preta funciona bem). $\mathrm{O}$ espectrômetro está pronto, faltando apenas calcular, construir e posicionar a escala de comprimentos de onda, o que também será detalhado a seguir. Se desejado, a haste pode ser feita em madeira. 
O dispositivo dispersor, como já mencionado na introdução, consiste de um CD. Usaremos aqui um CD gravável, do qual foi retirada a película de proteção, na qual se costuma descrever o conteúdo do CD. Retirada essa película, o CD passa a se comportar como uma rede de difração por transmissão, dado que a retirada da película de proteção do CD o tornará praticamente transparente à luz. Para uma melhor "transparência", escolha um CD gravável no qual a superfície de gravação seja clara (alguns CDs graváveis possuem uma tonalidade azul bastante escura; esses não resultam em boas redes de difração por transmissão). Descreveremos a seguir duas operações: o corte do CD, e em seguida, a retirada da película.

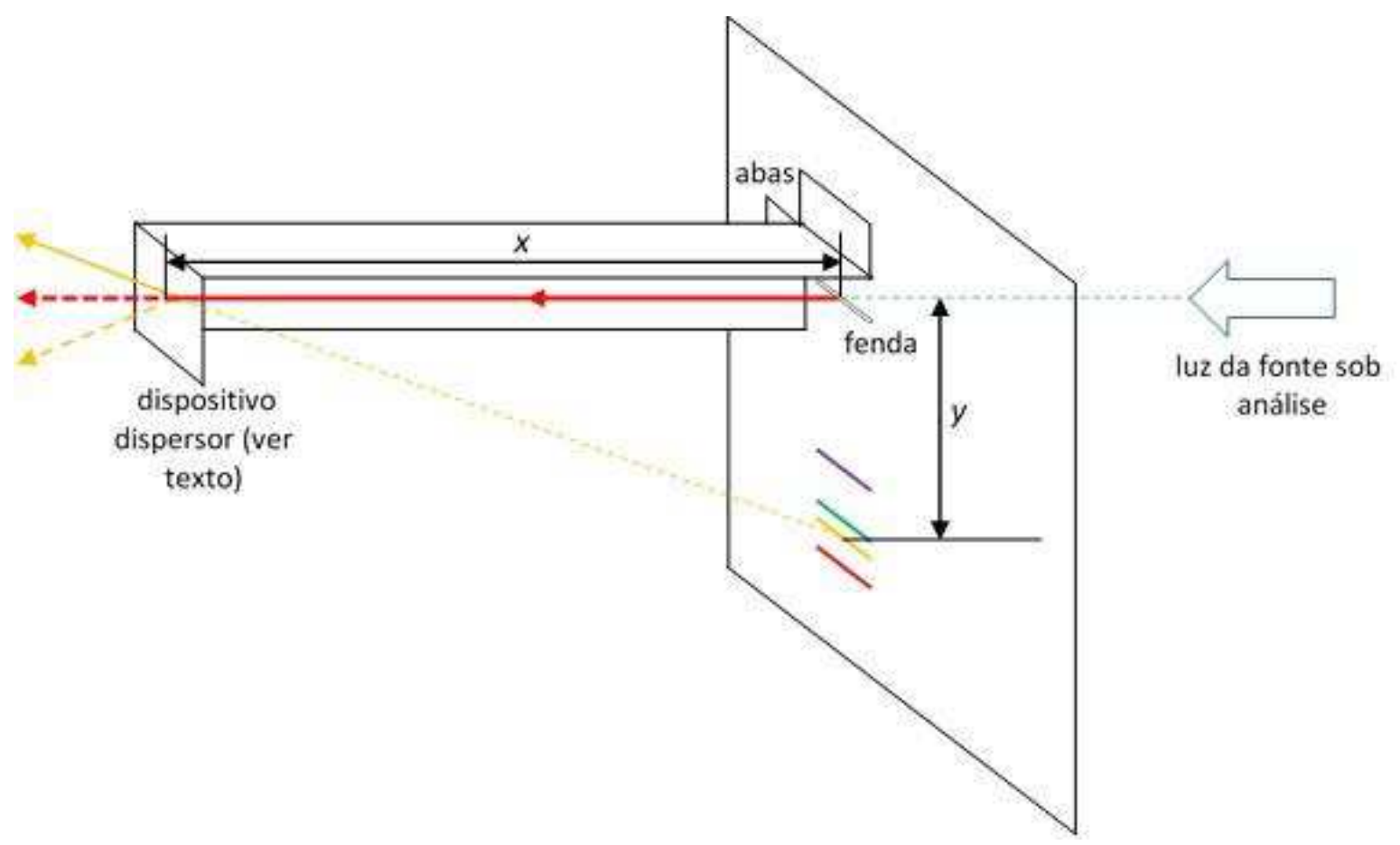

Fig. 4 - A luz oriunda da fonte sob análise atravessa uma fenda de $1 \mathrm{~mm}$ de largura por $15 \mathrm{~mm}$ de comprimento, feita numa cartolina de $15 \mathrm{~cm}$ por $15 \mathrm{~cm}$ (as dimensões são apenas indicativas). Uma tira, de $20 \mathrm{~cm}$ de comprimento, também de cartolina, dobrada em " $L$ " para maior rigidez, é fixada com fita adesiva. Na outra extremidade da tira, o dispositivo dispersor (pedaço de CD), dispersa (desvia) a luz que passou pela fenda; esse desvio é representado na figura para a componente amarelo-laranja da luz da fonte. O olho do observador, à esquerda do dispositivo dispersor, percebe esse desvio (seta menor, cheia, apontando para cima). Para ele, observador, a luz amarelo-laranja parece vir de algum local sobre a cartolina (essa é uma imagem virtual da fenda, em amarelo-laranja - no final da linha pontilhada). O mesmo vale para as outras cores. (Veja também a foto de um desses dispositivos já pronto, a seguir). 

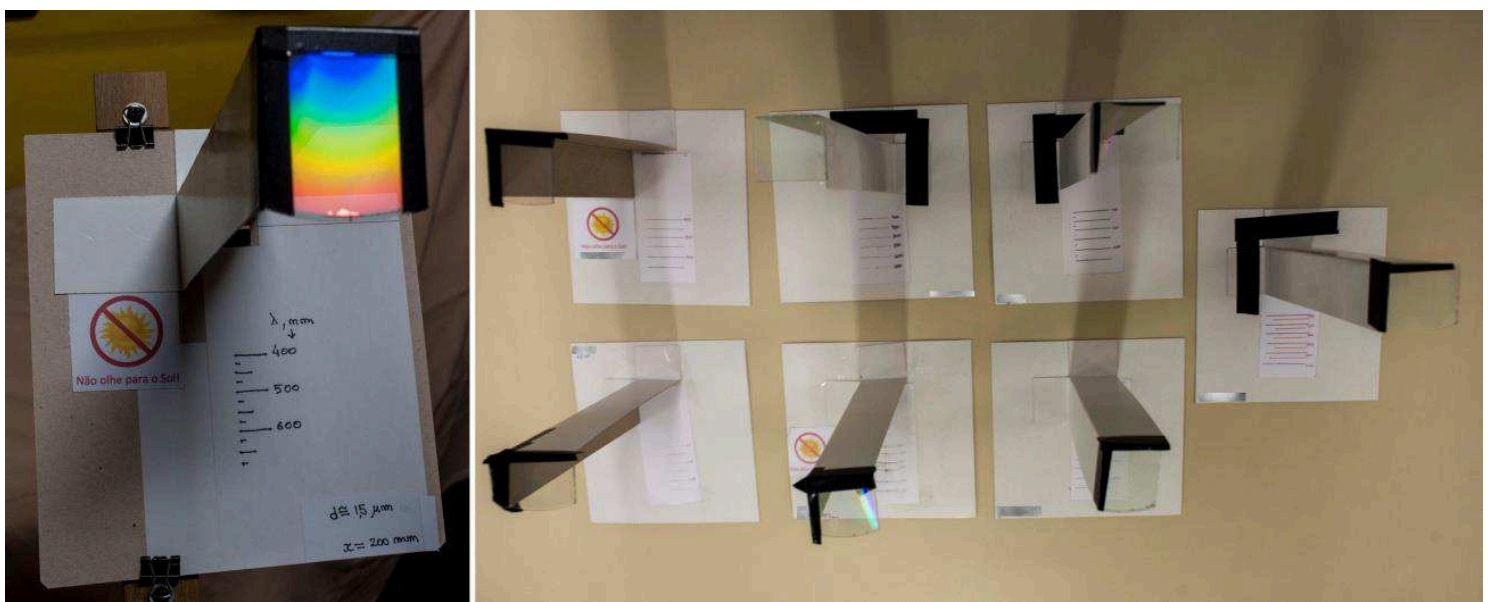

Fig. 5 -Imagem à esquerda: espectrômetro pronto. As belas cores no dispositivo dispersor (CD recortado) são provocadas pelo reflexo da luz de uma lâmpada fluorescente, no teto. Note a escala, e o zero desta (linha horizontal, próxima ao CD), alinhado com a fenda. À direita: espectrômetros confeccionados por estudantes de licenciatura em Física.

Com uma caneta própria para escrever em CDs, desenhe uma linha que passa pelo centro do $\mathrm{CD}$, e com base nesse diâmetro, marque uma região de formato aproximadamente quadrado, de $3 \mathrm{~cm}$ por $3 \mathrm{~cm}$, como mostra a Fig. 6.

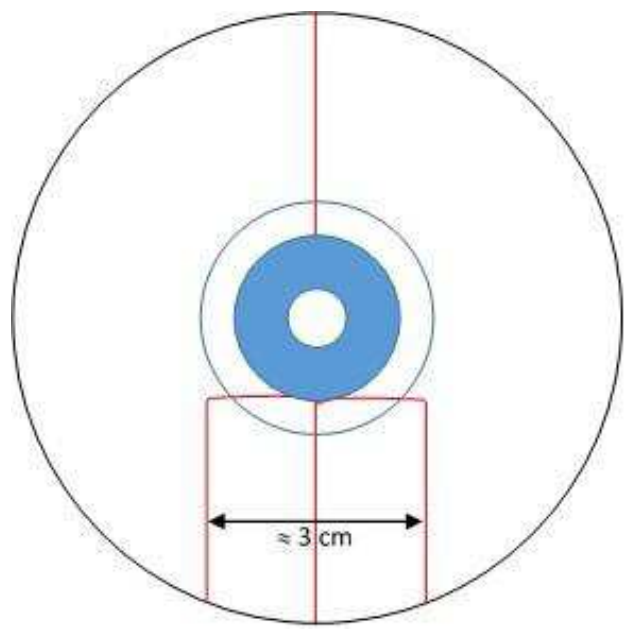

Fig. 6 -Delimitando a área de corte do CD gravável para a produção do dispositivo dispersor. Use uma caneta própria para escrever em CDs. A "técnica" para o corte e retirada da película é descrita no texto.

O corte do $\mathrm{CD}$ pode ser feito com uma tesoura grande; use a região das lâminas próxima ao cabo dessa; com isso, o esforço para cortar será menor. A retirada da película protetora também é muito simples: coloque o "quadrado" recortado do CD com a etiqueta para cima sobre uma mesa, e recubra-o por completo com fita adesiva. Pressione bem a fita contra o CD 
para garantir uma boa adesão, não há problema se as pontas das fitas adesivas colarem também na mesa (esse procedimento é descrito também em CATELLI; VICENZI, 2004).

Agora, descole devagar as fitas adesivas, e repare se a película sai aderida a elas (esse processo foi descrito de forma lúdica por alguns alunos como a "depilação" do CD). Se a película não sair, recole de volta as fitas e picote a extremidade do CD onde as fitas adesivas começam a descolar, digamos que seja a parte curva. Umas duas dezenas de picotes (com a ponta de um estilete, ou mesmo da tesoura) deverá ser suficiente; ao retomar o descolamento das fitas adesivas, a película do CD deverá sair aderida a elas (em caso contrário, retome o processo, até que a película saia).

Por fim, um conselho para aumentar a durabilidade desse maravilhoso dispositivo dispersor: não o segure com os dedos tocando a superfície da qual a película foi retirada. Isso a degradará com o tempo; segure-o pelas bordas. Ao montá-lo na coluna em "L" do espectrômetro, volte a superfície sensível para dentro, apontando para a fenda; isso aumentará bastante a vida útil do dispositivo.

O passo final para a conclusão do espectrômetro (exceto a construção da escala, que será explicada a seguir) consiste em colar o dispositivo dispersor na extremidade da coluna em "L" de cartolina; faça isso por meio de duas tiras estreitas de fita adesiva (sugerimos fita isolante preta). O resultado final aparece na Fig. 5, e nas diversas fotos que aparecem mais adiante, todas elas feitas com dispositivos análogos aos descritos nesse texto.

Agora, vamos à etapa que justifica o nome "espectrômetro": a construção da escala de comprimentos de onda. Para isso, precisamos de uma fonte de luz, de preferência fácil de encontrar no ambiente escolar. As lâmpadas fluorescentes tubulares são excelentes para essa propósito. O vapor de mercúrio contido no interior dessas lâmpadas emite luz em diversos comprimentos de onda; tomemos por exemplo a emissão no amarelo-laranja, de comprimento de onda médio ${ }^{9}$ igual a $578 \mathrm{~nm}$.

Aponte então o espectrômetro para uma lâmpada fluorescente tubular, que esteja a pelo menos uns dois metros de distância. Feche um dos olhos, e mantenha o outro bem próximo à rede de difração (pedaço de $\mathrm{CD}$, preparado como descrito mais acima); a fenda do espectrômetro deve estar aproximadamente paralela ao eixo do tubo da lâmpada. Na parte inferior do anteparo, abaixo da fenda, aparecerá o espectro de emissão da lâmpada (veja a figura 7). Lâmpadas fluorescentes de fabricantes (e tecnologias) diferentes produzirão eventualmente espectros também diferentes. Mas, em todos os casos, a emissão no amarelo-laranja estará presente, e será fácil de identificar.

Identificada a linha de emissão no amarelo-laranja, marque-a no anteparo. Uma técnica simples para efetuar a marcação com precisão consiste em segurar o dispositivo com a mão esquerda, e com a direita, posicionar uma tira de papel branco sobre o anteparo; olhando através

\footnotetext{
${ }^{9}$ São duas linhas de emissão próximas e intensas, uma de $577 \mathrm{~nm}$ e a outra, de $579,1 \mathrm{~nm}$. Para os propósitos desse trabalho, é razoável tomá-las como um única emissão, de comprimento de onda médio igual a $578 \mathrm{~nm}$. Esses comprimentos de onda foram retirados de <http://www.if.ufrgs.br/ marcia/lab8.pdf>.
} 
da rede de difração, posicione a borda dessa tira de modo a coincidir com a emissão do amarelo laranja. Depois, bastará marcar essa posição com um lápis, e prosseguir conforme descrito a seguir.

Agora, tome $m=1$ na expressão 1 , e calcule $d$, que nada mais é do que a distância entre duas trilhas adjacentes do $\mathrm{CD}^{10}$. Note que o ângulo $\theta$ é obtido diretamente através da expressão

$$
\theta=\arctan \frac{y}{x}
$$

Sendo y a distância da marcação (emissão em amarelo-laranja) até a fenda, e $x$ a distância da fenda ao dispositivo dispersor (rede de difração). Veja $x$ e $y$ na Fig. 4.

Se o comprimento de onda da emissão em amarelo-laranja for expresso em $\mathrm{mm}$ $\left(578 \times 10^{-6} \mathrm{~mm}\right)$, o parâmetro " $d$ ” terá também essa unidade, mm. O inverso desse parâmetro, $1 / d$, é o número de linhas por mm do dispositivo dispersor. O cálculo efetuado para o dispositivo dispersor empregado nas fotos apresentadas até aqui levou ao valor de $1,502 \times 10^{-3} \mathrm{~mm}$ para $d$, e 666 linhas por mm para $1 / d$.

De posse do valor do parâmetro " $d$ ", $(1 / 666) \mathrm{mm}$, usa-se iterativamente a expressão 1 para calcular a posição dos comprimentos de onda correspondentes, por exemplo, a $400 \mathrm{~nm}$, $450 \mathrm{~nm}, 500 \mathrm{~nm}, 550 \mathrm{~nm}, 600 \mathrm{~nm}$ e $650 \mathrm{~nm}$. (Se desejado, é possível colocar divisões intermediárias, de 25 em 25 nm, como nas imagens das Fig. 6 e 7.)

A título de exemplo, apresentamos esse conjunto de cálculos na tabela 1, com os valores $y$ arredondados para décimos de mm, para uma distância fenda-rede " $x$ " igual a $200 \mathrm{~mm}$ (equação 2), e para "d" = (1/666) mm (equação 1). (Ao passar esses dados para uma escala em papel, à mão, arredonde os valores para mm).

Tabela 1 - Valores do parâmetro y (ver texto acima e figura 4), para os comprimentos de onda indicados. Esses valore de y gerarão a escala, que deverá ser desenhada cuidadosamente numa tira de papel branco, e em seguida colada no espectrômetro. Como reforçado no texto, a posição “ 0 ” da escala deverá estar alinhada com a fenda.

\begin{tabular}{|l|l|l|l|l|l|l|}
\hline$\lambda(\mathrm{nm})$ & 400 & 450 & 500 & 550 & 600 & 650 \\
\hline$y(\mathrm{~mm})$ & 55,3 & 62,9 & 70,7 & 78,8 & 87,3 & 96,2 \\
\hline
\end{tabular}

A tarefa final consistirá em transpor, numa tira de papel branco, os valores de " $y$ ", e em seguida colar essa tira no dispositivo. Não esqueça de marcar na tira de papel a posição "0 (zero) mm"; essa posição deverá estar alinhada com a fenda.

Como usar o espectrômetro? Reveja a Fig. 4. Feche um olho, aproxime o outro olho do dispositivo dispersor (o pedaço de $\mathrm{CD}$ ) e aponte a fenda do dispositivo para uma fonte de

\footnotetext{
10 Uma exploração curiosa desse parâmetro " $d$ " pode levar a estimativas bastante plausíveis do tamanho de um bit; veja <https://periodicos.ufsc.br/index.php/fisica/article/viewFile/6278/12771>. (Pense e responda: qual o tamanho de um bit?)
} 
luz, uma lâmpada no teto, por exemplo. Olhe para a escala; depois de algumas variações no alinhamento do dispositivo, você verá o espectro da lâmpada como se estivesse "projetado" sobre ela. Se o intuito for efetuar medições, as "fontes extensas" de luz, tais como lâmpadas fluorescentes tubulares, paredes brancas iluminadas pelo Sol, lâmpadas residenciais de LED, e outras, são as mais indicadas. Lâmpadas de iluminação pública, distantes, aparecerão como "pontos", e dificultarão um pouco mais as leituras nas escalas. É importante também tomar cuidado com reflexos de lâmpadas situadas às costas do observador, elas também podem prejudicar a visualização e medição. Trataremos a seguir de algumas das múltiplas possibilidades de uso desse espectrômetro.

\section{Resultados: algumas sugestões de uso do espectrômetro}

As Fig. 7 e 8 já adiantam uma possível exploração, que pode ser feita sem mesmo sair do interior da sala de aula. O espectro das lâmpadas fluorescentes do teto se assemelhará com o apresentado na Fig. 7. Se as lâmpadas foram trocadas mais recentemente, o espectro talvez se assemelhe mais ao da Fig. 8, à esquerda, de lâmpadas fluorescentes compactas.

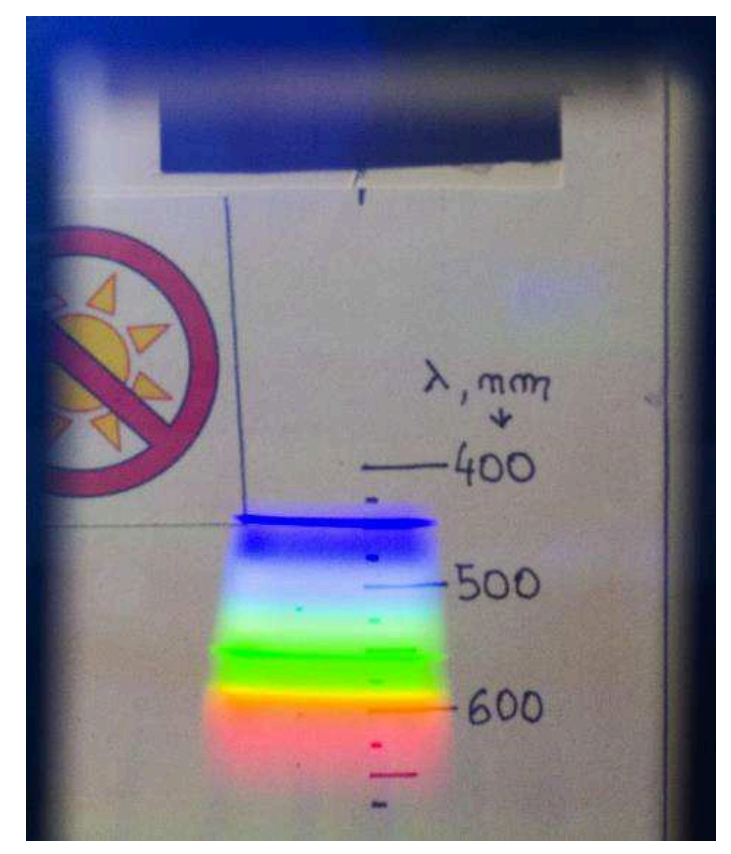

Fig. 7 - Espectro de uma lâmpada fluorescente tubular residencial, obtido por meio do dispositivo descrito no texto, e fotografado através da rede de difração (CD, ver texto). Note as linhas de emissão do mercúrio destacando-se sobre o espectro contínuo. Note também que, por exemplo, a raia anil tem comprimento de onda de $436 \mathrm{~nm}^{11}$; na escala, na figura, percebese que ele é algo menor que $450 \mathrm{~nm}$, o que é um resultado aceitável dada a simplicidade do dispositivo de medição aqui proposto.

\footnotetext{
${ }^{11}$ Ver, por exemplo, <http://www.if.ufrgs.br/ marcia/lab8.pdf>.
} 
Se os estudantes desejarem registrar esses espectros, isso pode ser feito simplesmente colocando em frente à lente da câmara de seus telefones celulares um pedaço de $\mathrm{CD}$, preparado como descrito no item anterior. Se a imagem assim obtida incluir apenas uma lâmpada, distante alguns metros, o espectro terá uma resolução impressionante; vale a pena propor aos alunos essa tarefa. Em seguida, alguns dos comprimentos de onda registrados nas fotos podem ser quantificados de forma aproximada; com o auxílio do espectrômetro, os estudantes poderão analisar a mesma lâmpada, identificar os comprimentos de onda que chamaram a atenção na foto, e por fim, atribuir-lhes valores em nanômetros, a partir da leitura na escala.

Um detalhe adicional sobre fotografar espectros colocando CDs em frente à lente da câmara: se as fontes de luz estão distantes (lâmpadas de postes de iluminação, por exemplo) as fontes serão "pequenas", e o espectro se assemelhará ao obtido ao observar uma fonte próxima através de uma fenda, como é feito ao empregar o espectrômetro. A vantagem é a de poder gravar a imagem em foto e a desvantagem é a de não poder contar com a escala, para medições.

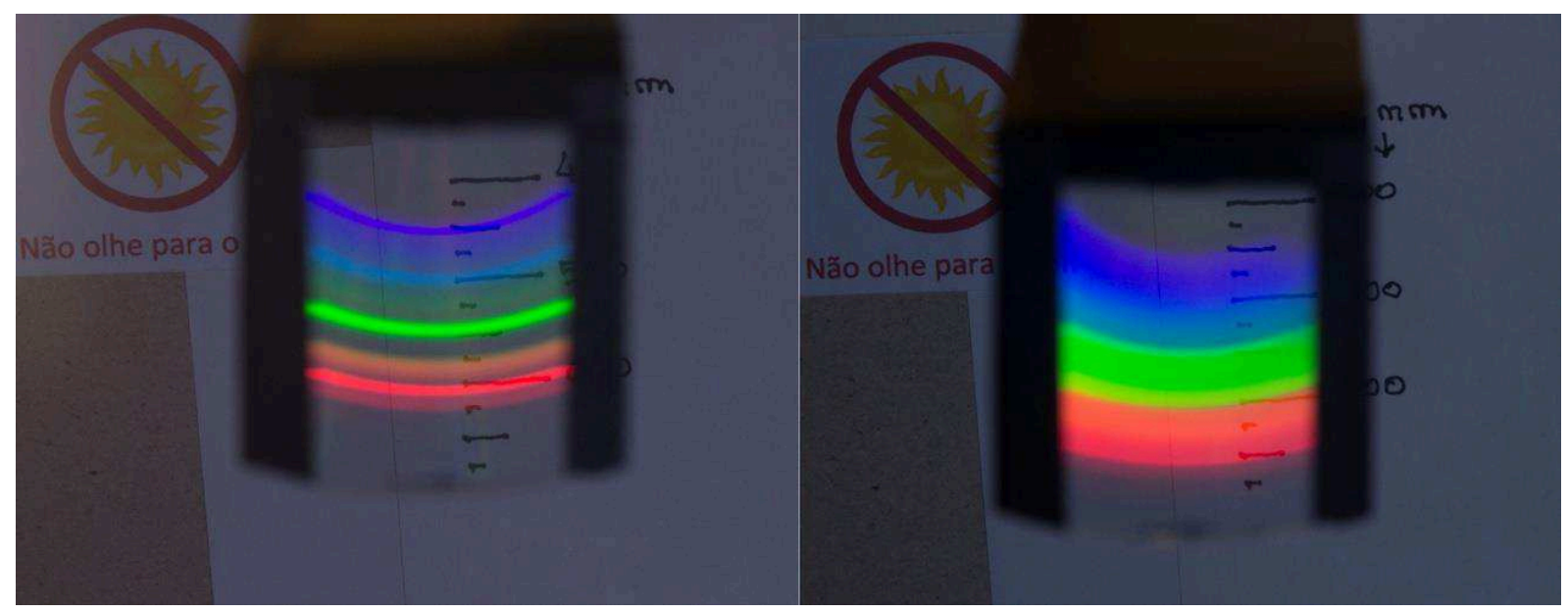

Fig. 8 - À esquerda: espectro de uma lâmpada fluorescente compacta. A largura da fenda é de aproximadamente $1 \mathrm{~mm}$. Na imagem à direita, é possível responder à pergunta: porque a fenda tem que ser estreita? Nessa imagem, obtida com uma largura de fenda de 4 mm, as linhas se alargam e se sobrepõem; não é mais possível associar-lhes comprimentos de onda.

O comprimento de onda da emissão na cor anil (Fig. 8, à esquerda) poderá ser identificado, por exemplo, como tendo um pouco menos de $450 \mathrm{~nm}$; o verde, nessa mesma figura, cai em $550 \mathrm{~nm}$, também aproximadamente. Aqui, o professor poderá aproveitar a ocasião para mencionar que é nessa faixa, em torno dos $550 \mathrm{~nm}$, que o olho humano responde com a maior eficiência (HALLIDAY; RESNICK; WALKER, 2014, p. 2).

A respeito da incerteza das medições feitas com o espectrômetro, um valor razoável é algo em torno de $\pm 15 \mathrm{~nm}$, quando fontes extensas são observadas, com o olho colocado próximo à rede. Essa incerteza é algo maior que a metade das divisões da escala, que crescem de 
$25 \mathrm{em} 25 \mathrm{~nm}$. Para fontes distantes e portanto aproximando-se de fontes pontuais, o alinhamento fonte - fenda - rede - olho pode aumentar essa incerteza. Na Fig. 8, à esquerda, as linhas aparecem curvas, e isso aumentaria a incerteza da medição. No entanto, esse efeito de curva ocorre quando o observador (nesse caso, a objetiva da lente da câmera fotográfica) está colocado relativamente distante da rede. Nas observações feitas por "observadores humanos", o olho deve ser colocado próximo à rede, e nesse caso, as linhas aparecerão mais retas. Isso pode ser comprovado afastando e aproximando o olho da rede de difração, por ocasião da observação.

Cabe aqui um alerta, e esse alerta aparece graficamente nas Fig. 5, 7 e 8 (um símbolo gráfico de "proibido" superposto à imagem do Sol). NUNCA APONTE O ESPECTRÔMETRO PARA O SOL, EM NENHUMA HIPÓTESE! Há risco de lesão irreversível na retina, e isso deve ser enfatizado aos estudantes várias vezes, antes da proposta de construção do espectroscópio, durante a construção, e principalmente depois, durante a fase de exploração. Para explorar o espectro da luz do Sol de forma segura, basta apontar o espectrômetro, por exemplo, para uma parede branca, diretamente iluminada por ele. Ou apontá-lo para a lua cheia. Outras fontes de luz podem ser potencialmente perigosas para a retina: arcos de solda elétrica, ou lâmpadas de iluminação pública, por exemplo. Essas últimas acabam por representar um risco menor, por estarem na maior parte das vezes distantes, na extremidade de postes de iluminação. De longe (a mais de 4 ou $5 \mathrm{~m}$ ), elas poderão ser observadas com segurança através do espectroscópio, ou fotografadas com telefone celular através de CDs "depilados".

Na Fig. 9 é apresentada a imagem do espectro contínuo de uma lâmpada incandescente; o espectro do Sol, visualizado numa parede branca por ele iluminada, também é contínuo. Outra exploração possível, partindo da ideia de analisar a luz do Sol olhando para uma parede branca por ele iluminada: se a parede for, por exemplo, vermelha, o espectrômetro detectará uma faixa vermelha intensa, e eventualmente, nenhum azul ou lilás, e também pouco (ou nenhum) verde e amarelo. Mas, e se a parede apresentar coloração amarelo claro, ou rosa? O resultado pode ser surpreendente; veja o parágrafo (mais adiante) onde é sugerida a exploração do efeito de filtros por meio do espectrômetro. Ao falar de espectros contínuos, cabe destacar um aspecto importante, associado à medida de comprimentos de onda: quando é feita referência, digamos, à cor vermelha, na maior parte das vezes se trata de uma faixa de comprimentos de onda; então, a rigor, não é possível associar um único comprimento de onda à cor vermelha. O costume é fazer referência aos extremos dessa faixa, de $600 \mathrm{~nm}$ à $700 \mathrm{~nm}$, aproximadamente. Todos os comprimentos de onda compreendidos entre esses dois extremos corresponderiam a diferentes "tons" da cor vermelha. 


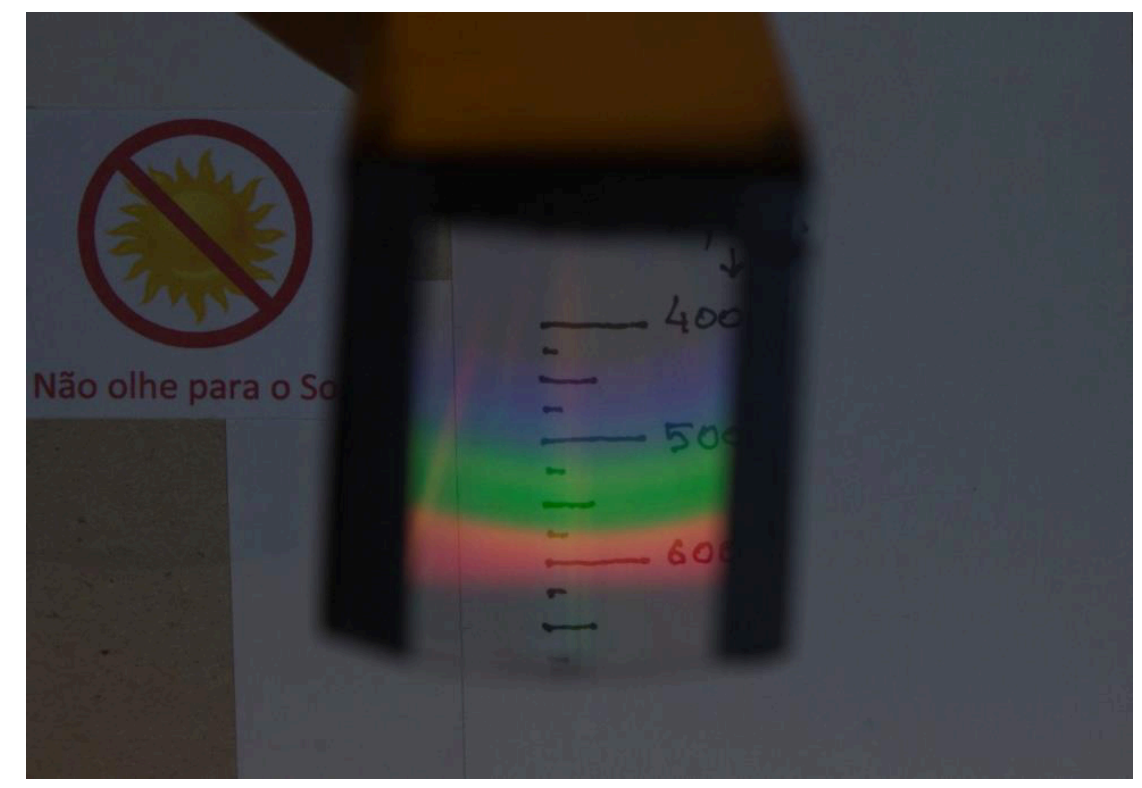

Fig. 9 - Espectro contínuo de uma lâmpada de filamento. Um espectro contínuo como esse é visto ao olhar para uma parede branca, intensamente iluminada pelo Sol.

Outro resultado interessante pode ser obtido colocando um filtro em frente à fenda do espectrômetro. Na Fig. 10, metade da fenda foi obstruída com um filtro feito em papel celofane lilás (imagem à esquerda) e em papel celofane verde (imagem à direita). Nessas fotos, a fenda foi iluminada com uma lanterna LED, que produz um espectro praticamente contínuo. (O leitor notará que, no espectro da luz de LED que não passa pelo filtro, "falta" uma parte do espectro, compreendida entre o violeta e o verde (de $425 \mathrm{~nm}$ a $525 \mathrm{~nm}$, aproximadamente), e por isso ele não pode ser considerado contínuo em toda a faixa de comprimentos de onda do visível, como seria o espectro de uma lâmpada de filamento. A lanterna de LED foi usada para essas fotos devido à sua maior intensidade, quando comparada à lâmpada de filamento).

O leitor notará também que a cor lilás (imagem à esquerda, na Fig. 10) resulta, predominantemente, da composição de uma faixa de comprimentos de onda na região do vermelho e de uma faixa de comprimentos de onda na região do violeta. Também convém chamar a atenção dos alunos que essa cor lilás (visível na foto na região da fenda) não aparece no espectro, o que significa que ela não é uma cor "pura" como as cores que aparecem no espectro de decomposição da luz branca. A cor lilás provém da composição de (pelo menos) duas faixas de cores diferentes, vermelho e violeta, essas sim, presentes no espectro.

Cabe um comentário adicional sobre como as fotos da Fig. 10 foram feitas: como mencionado acima, uma lanterna de LED foi apontada diretamente para a fenda, de modo que a luz que passou por ela é refletida de volta sobre si mesma (mancha clara sobre a fenda) e dispersada (as cores que aparecem sobre a escala). Dessa vez, a luz refletida pela rede de dispersão que incide na escala é capturada diretamente pela câmara fotográfica, diferentemente, portanto, das fotos das Fig. 7 e 8 . O espectro assim obtido por reflexão é de pouca intensidade, e necessita de 
uma sala escura para ser percebido visualmente. As fotos foram obtidas regulando a câmara para longos tempos de exposição (tipicamente $15 \mathrm{~s}$ ), e por isso a luz dispersada aparenta ser mais intensa do que ela seria, se percebida a olho nu, através do espectrômetro.
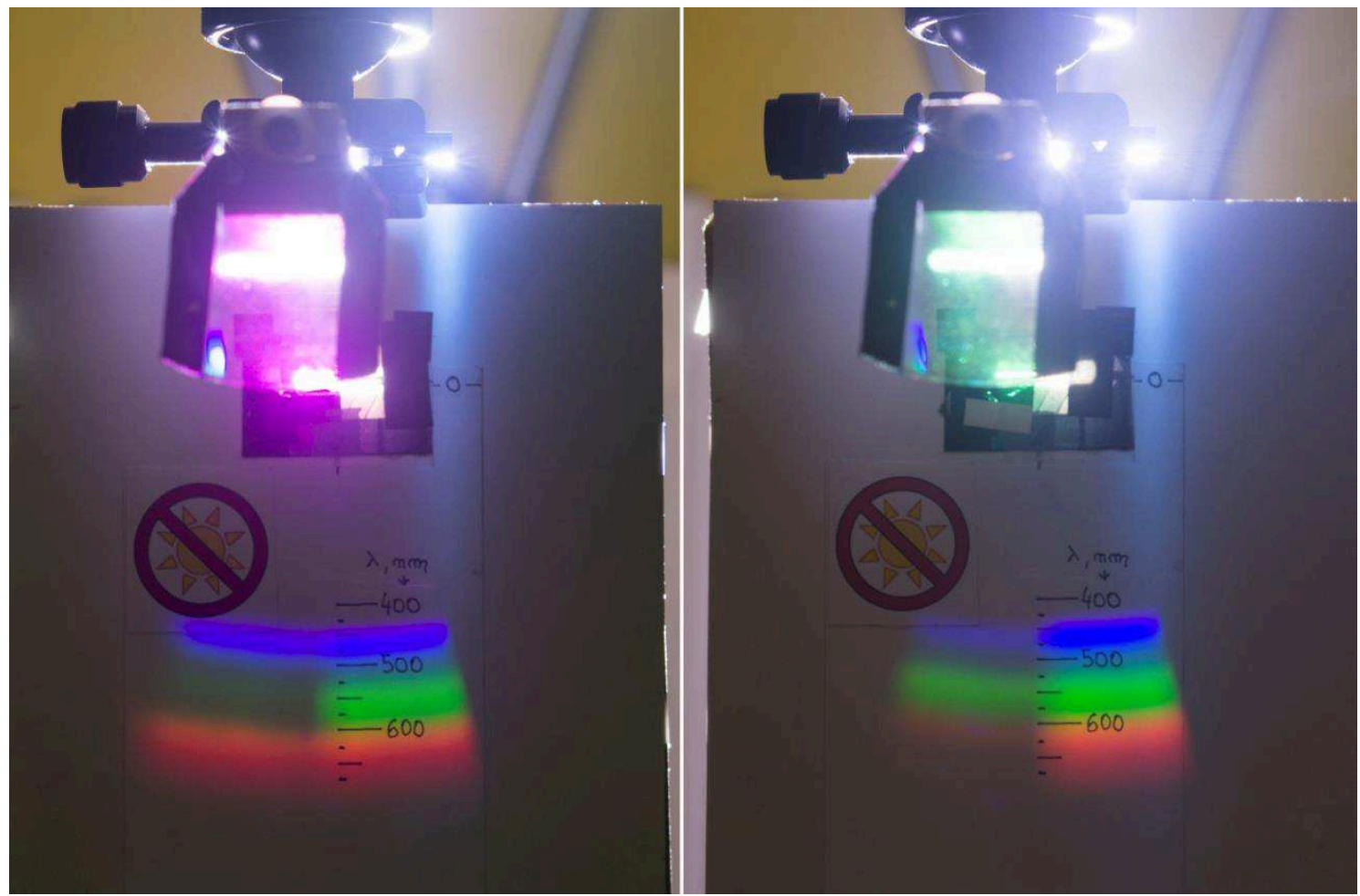

Fig. 10 - Na imagem à esquerda, um filtro lilás sobrepõe-se à metade da fenda, de modo que o espectro (quase) contínuo da lâmpada de LED aparece à direita, e o espectro da luz que passou pelo filtro aparece à esquerda. Na imagem à direita, um filtro verde foi sobre posto à metade da fenda. Esse filtro "deixa passar" o verde (o que seria de esperar), mas deixa passar também um pouco de vermelho e de violeta. Os tons lilás e esverdeado podem ser percebidos na imagem à esquerda e na imagem à direita, respectivamente, sobre o elemento dispersor $(C D)$.

Há muitos outros resultados que poderia ser apresentados; para não alongar excessivamente o artigo, alguns deles serão apenas mencionados na conclusão.

\section{Conclusão}

O valor didático do espectrômetro aqui proposto inclui a possibilidade de medição, mas o que pode empolgar de fato alguns estudantes é a possibilidade praticamente ilimitada de exploração dos espectros das mais diversas fontes de luz. A chama do fogão a gás, as emissões de lâmpadas de LED, a diferença entre lâmpadas de temperatura de cor de $6500 \mathrm{~K}$ e $3000 \mathrm{~K}$, a emissão das lâmpadas (agora “antigas”!) de filamento, a lista é praticamente interminável. 
No que diz respeito aos espectros e à espectroscopia, a construção e a exploração permitirá a exploração de termos tais como "espectro contínuo" (Fig. 7), espectros de linhas (as "linhas" mais intensas que se sobressaem, na Fig. 7), espectroscopia de absorção (Fig. 10), e assim por diante.

Do ponto de vista da medida, operação que consiste em associar um número a um elemento pertencente ao conjunto de uma determinada grandeza, cabe um comentário a respeito das "cores puras" (aquelas presentes no espectro contínuo da luz branca). Essas poderão ser representadas por comprimentos de onda, e a um dado comprimento de onda corresponderá uma única porção ("linha") do espectro da luz branca. Esse é o caso das "cores do arco íris": violeta, azul, verde, amarelo, laranja, vermelho. Mas outras cores (a imensa maioria das que percebemos no dia-a-dia) são obtidas a partir da composição de diversos desses comprimentos de onda, ou de determinadas faixas de comprimentos de onda. Esse aspecto, intrigante aos olhos dos alunos, é exemplificado na foto à esquerda na figura 10, onde pode ser percebido que a cor lilás (visível na região da fenda e sobre o $\mathrm{CD}$ ), que não pode ser encontrada em nenhum lugar no espectro da luz branca, é de fato a combinação de duas faixas de comprimentos de onda, uma na região violeta e a outra, na região vermelha do espectro. Então, respondendo à indagação expressa na introdução, não é possível associar um número (comprimento de onda) à cor lilás; precisaríamos de (pelo menos) dois números (comprimentos de onda) para quantificá-la.

Um aspecto que também cabe destacar é a grande facilidade de fabricação do dispositivo. Ela pode ser desenvolvida no ambiente da sala de aula, com materiais do quotidiano, e com custo associado praticamente nulo. Não é o caso de outros espectrômetros (OLIVEIRA; LEITE, 2016; GARCIA; KALINOWSKI, 2004; LÜDKE, 2010), os quais, se por uma lado oferecem medidas mais precisas, por outro lado são de construção e ajuste mais elaborados.

$\mathrm{Na}$ perspectiva do ambiente da sala de aula, a construção (manual) da escala de comprimentos de onda poderá se revelar um "exercício" interessante, e de fácil consecução. Como esse exercício estará associado ao projeto de construção do espectrômetro, a motivação dos alunos ao executa-lo poderá ser maior.

Por fim, o espectrômetro aqui apresentado, apesar do nome pretencioso (ele permite de fato medir comprimentos de onda, mas a incerteza associada a essa medidas é relativamente grande) tem talvez seu maior valor no fato de se constituir numa oportunidade quase ilimitada de exploração de características das mais diversas fontes de luz, e é aí certamente que reside seu maior valor. Os professores que propuserem a seus estudantes a confecção e exploração desse dispositivo, seguramente perceberão o potencial que ele encerra nesse sentido.

\section{Bibliografia}

CATELLI, F.; VICENZI, S. Interferômetro de Michelson. Caderno Brasileiro de Ensino de Física, v. 21, ed. especial, p. 350-358, nov. 2004. 
CATELLI, F.; PEZZINI, S. Observando espectros luminosos: espectroscópio portátil. Caderno Brasileiro de Ensino de Física, v. 21, ed. especial, p. 339-344, nov. 2004.

CATELli, F.; HERBER, J.; MENEGOTTO, J. C.; KESSLER, S. L. O que é uma raia espectral? A Física na Escola, v. 7, n. 2, p. 70-72, 2006.

GARCIA, N. M. D.; KALINOWSKI, H. J. Um espectroscópio simples para uso individual. Caderno Brasileiro de Ensino de Física, v. 21, ed. especial, p. 332- 338, nov. 2004.

HALLIDAY, D.; RESNICK, R.; WALKER, J. Fundamentos de Física: Óptica e Física Moderna. 9. ed. Rio de Janeiro: LTC, 2014. v. 4.

HUYGENS, H. C. Treatise on Light (1704). Disponível em: <https://ia600307.us.archive.org/13/items/treatiseonlight031310mbp/treatiseonlight031310mbp.pdf>.

KNIGHT, R. D. Física 2: uma abordagem estratégica. 2. ed. Porto Alegre: Bookman, 2009. v. 2

LÜDKE, E. Um espectrofotômetro de baixo custo para laboratórios de ensino: aplicações no ensino da absorção eletrônica e emissão de fluorescência. Revista Brasileira de Ensino de Física, v. 32, n. 1, p. 1506, 2010.

MARbURGER, J. H. What is a photon? The Physics Teacher, v. 34, p. 482-486, nov. 1996.

MASSONI, N. T. Epistemologias do Século XX. Porto Alegre: Instituto de Física, UFRGS, 2005. Disponível em: <https://www.if.ufrgs.br/tapf/v16n3_Massoni.pdf >.

NEWTON, I. Optics: a Treatise of Reflexions, Refractions, Inflections and Colours of Light (1704). Disponível em: <http://brizhell.org/Newton_Speckles/Opticks\%20-\%20scan\%20from \%20original\%20manuscript\%20-\%20I.\%20Newton.pdf $>$.

OLIVEIRA FILHO, K. Espectroscopia. Disponível em: <http://astro.if.ufrgs.br/telesc/espectroscopia.html>. Acesso em: 26 abr. 2017.

OLIVEIRA, P. C. C.; LEITE, M. A. P. Espectrofotometria no Ensino Médio: construção de um fotômetro de baixo custo e fácil aquisição. Química nova na Escola, v. 38, n. 2, p.181-184, mai. 2016.

TIPLER, P. A.; MOSCA, G. Física para cientistas e engenheiros: eletricidade e magnetismo, óptica. 6. ed. Rio de Janeiro: LTC, 2011. v. 2. 